IZA DP No. 4963

\title{
Priming Cooperation in Social Dilemma Games
}

Michalis Drouvelis

Robert Metcalfe

Nattavudh Powdthavee

May 2010 


\title{
Priming Cooperation in Social Dilemma Games
}

\author{
Michalis Drouvelis \\ University of York
}

Robert Metcalfe

University of Oxford

\author{
Nattavudh Powdthavee \\ Nanyang Technological University \\ and IZA
}
Discussion Paper No. 4963
May 2010

IZA

P.O. Box 7240

53072 Bonn

Germany

Phone: +49-228-3894-0
Fax: +49-228-3894-180
E-mail: iza@iza.org

Any opinions expressed here are those of the author(s) and not those of IZA. Research published in this series may include views on policy, but the institute itself takes no institutional policy positions.

The Institute for the Study of Labor (IZA) in Bonn is a local and virtual international research center and a place of communication between science, politics and business. IZA is an independent nonprofit organization supported by Deutsche Post Foundation. The center is associated with the University of Bonn and offers a stimulating research environment through its international network, workshops and conferences, data service, project support, research visits and doctoral program. IZA engages in (i) original and internationally competitive research in all fields of labor economics, (ii) development of policy concepts, and (iii) dissemination of research results and concepts to the interested public.

IZA Discussion Papers often represent preliminary work and are circulated to encourage discussion. Citation of such a paper should account for its provisional character. A revised version may be available directly from the author. 
IZA Discussion Paper No. 4963

May 2010

\section{ABSTRACT}

\section{Priming Cooperation in Social Dilemma Games}

Research on public goods mainly focuses its attention on the ability of incentives, beliefs and group structure to affect behaviour in social dilemma interactions. This paper investigates the pure effects of a rather subtle mechanism on social preferences in a one-shot linear public good game. Using priming techniques from social psychology, we activate the concept of cooperation and explore the extent to which this intervention brings about changes in people's voluntary contributions to the public good and self-reported emotional responses. Our findings suggest that priming cooperation increases contribution levels, controlling for subjects' gender. Our priming effect is much stronger for females than for males. This difference can be explained by a shift in subjects' beliefs about contributions. We also find a significant impact of priming on mean positive emotional responses.

JEL Classification: C92, D01, H41

Keywords: $\quad$ priming, contributions, beliefs, emotional responses, public goods experiments

Corresponding author:

Michalis Drouvelis

Department of Economics and Related Studies

University of York

Heslington, York, YO10 5DD

United Kingdom

E-mail: md539@york.ac.uk

\footnotetext{
* Financial support from the University of York is gratefully acknowledged. We would like to thank Vincent Crawford, Rachel Croson, Paul Dolan, Ivo Vlaev, and Andrew Oswald for their comments.
} 


\section{Introduction}

Many important economic and social interactions are characterised by publicgood-type games in which individuals' personal interests are at odds with group benefits. Situations such as voting, tax compliance, corruption, teamwork, environmental protection are real-life instances demonstrating the tension between individual and collective rationality and thus, the experimental investigation of why people cooperate with each other in such situations has been of major interest to economics (see Ledyard, 1995 for a review on earlier findings). By now a great deal of research has documented that, while free riding is predicted within the standard economic model, people do not always follow their pure self-interest, exhibiting social preferences (see Fehr and Fischbacher, 2002 and DellaVigna, 2009 for extensive reviews).

In particular, laboratory research on public goods games examines the nature of the mechanisms that may foster cooperation and bring about behavioural change. On the one hand, most part of the experimental literature explores the effects of explicit interventions on cooperative behaviour. Such interventions comprise introducing sanction and reward systems (e.g., Fehr and Gächter, 2000, 2002; Sefton et al., 2007; Sutter et al., forthcoming), establishing a leader (e.g., Güth, et al., 2007; Levati, et al., 2007), and facilitating communication (e.g., Isaac and Walker, 1988; Bochet et al, 2006). These explicit mechanisms have been found to significantly impact on the provision of public goods and help reduce the extent to which people free ride.

On the other hand, and to a much lesser extent, experimental studies investigate whether and if so, how pro-social behaviour in social dilemmas is influenced by rather subtle interventions, such as framing (e.g., Andreoni, 1995; Dufwenberg et al, 2006; Cubitt et al, 2008) and non-binding cooperation defaults (Altmann and Falk, 2009). In this paper, we contribute to this literature by investigating the effects of another subtle intervention, namely, priming, on free riding behaviour in a social dilemma game. Priming, which is formally defined as "the procedural feature that some previously activated information impacts on the processing of subsequent information" (see Hertel \& Fiedler, 1998), is a prominent topic in social and cognitive psychology (e.g., Hertel \& Fiedler, 1994; Hertel \& 
Fiedler, 1998; Kay et al., 2004; Smeesters et al., 2003; Utz et al., 2004). ${ }^{2}$ For instance, it has been demonstrated that priming people to think about the last two digits of their social security number influences their willingness to pay for different types of goods (see Ariely et al., 2003). In their meta-analysis, Bargh and Ferguson (2000) found that social behaviour can be carried out without the interaction of the conscious acts of will and guidance, and priming will have a great deal on this subconscious behaviour, while Vlaev and Dolan (2009) suggest that priming can be used to actively change a range of behaviours, especially health and altruistic behaviours.

Inspired by the existing psychological literature, as well as by recent economics research indicating that elements of the choice environment affect people's pro-social behaviour, we address a question that is of special interest to economists (and also to economic policy-makers): Does priming make people more socially oriented in an incentivised environment where personal and collective interests are at odds? This is our novel contribution to the literature as no previous studies have investigated priming in an economic game where there is a clear financial incentive to free ride.

Priming has little to do with the standard economic model. Taking DellaVigna's (2009) description of non-standard factors in economics, priming is part of non-standard decision-making, and the implications of priming are large. It essentially suggests that if priming impacts on our behaviours, and does not impact on different information and different incentives, then the standard economic model is missing a significant aspect of individual behaviours. For this reason, it seems important to the economics literature to examine whether priming can be successfully used to encourage behaviours that are deemed essential to both individual and social advancements.

We tested whether activating the concept of cooperation through the use of priming techniques adapted from social psychology (see Bargh et al, 2001) leads people to behave pro-socially. We assumed that by heightening the accessibility of the idea of cooperation in a social dilemma, individuals would raise their voluntary contributions towards the common resource, as priming would act a subconscious reminder of the concept of cooperation.

\footnotetext{
${ }^{2}$ At this point, it is worth emphasising that priming is a distinct notion from framing. The concept of framing refers to the re-description of a logically equivalent decision problem in a positive or negative light, whereas, priming refers to the implicit activation of some previously stored knowledge, without requiring the re-description of the decision problem.
} 
Specifically, our concern is with whether priming impacts on revealed preferences, and the affective responses to those preferences. In terms of revealed preferences, we analyse the actual contributions made by subjects to a one-shot public good game. This provides us with a behavioural measure of how much subjects are prepared to respond practically to our subtle intervention by contributing their own resources to the public good. In terms of affective responses, we use subjects' selfreported emotions, which are a complementary tool for identifying whether subjects respond to others' contributions differently depending on the primes. Our interest in emotions stems from the fact that they have played a central role in the social preferences literature in various contexts (e.g., Bosman and van Winden, 2002, forthcoming; van Winden et al., 2008). In particular, regarding the setting of social dilemmas, recent laboratory research indicates that emotions generate and explain economic behaviour, with positive/negative emotions being connected with positive/negative concerns (e.g., Fehr and Gächter, 2002; Cubitt et al., 2008).

Summarising the main findings of our study, they suggest that priming subjects to cooperation increases their voluntary contributions significantly, controlling for subjects' gender. With respect to priming, positively primed females behave in a more generous manner than neutrally primed females and positively primed males. This gender effect can be explained by a difference in their beliefs about others' contributions. Turning to self-reported emotional responses, our findings record a positive and significant impact that priming has on individuals' emotional responses, which is more pronounced with respect to their mean positive emotions (namely, happiness, joy and warmth).

The remainder of the paper is organised as follows. Section 2 describes the design and the hypotheses for our experiment. Our experimental findings are presented in Section 3. Section 4 concludes and discusses the implications of priming for the design of public policy.

\section{Experimental Design \& Hypotheses}

\subsection{Our framework: The linear public goods game}

The main framework for our analysis is the linear public goods game (see Ledyard, 1995, for an overview), which is a stylized model in the experimental literature to study cooperation issues. In summary, this game captures the pure tension between individual gains and social efficiency. The structure of the linear public 
goods game for our experiment is as follows. A group of 3 participants is randomly formed and each participant within a group receives a fixed amount of 20 tokens. We refer to this as his/her endowment. Participants simultaneously have to decide how many (out of 20) tokens to keep for themselves and how many to contribute to the public good, described to subjects as a project. Each token contributed to the public good is deducted from this participant's private account (that is, 20 - his/her contribution). For each token a participant keeps for himself/herself, he/she has a return of 1 money unit, whereas, for each token he/she contributes to the public good, each member of the group - regardless of whether someone has contributed or not has a return of 0.5 money units, creating a total benefit of 1.5 tokens for the entire group. This implies that the total earnings from the contributions to the public good are equally distributed among all members of the same group. The payoff for participant $i$ is given as follows:

$\pi_{i}=20-g_{i}+0.5 \cdot \sum_{j=1}^{n} g_{j}$

Since the cost for the contributing subject is 1 money unit per token, while the private return is only 0.5 money units, a selfish participant has always an economic incentive to contribute nothing to the public good and rely on the contribution of other participants. Yet, Pareto efficiency requires that all participants fully contribute their endowment to the public good (in this case each participant receives an income equal to 30 money units, which is greater than his/her initial endowment).

\subsection{Design}

The main focus of our experiment is to assess how people respond to priming both behaviourally and emotionally. As tools to measure these effects, we use contributions to public goods (i.e. revealed preferences) and self-reported emotional responses. Our experimental design consists of two treatments: one in which people are neutrally primed and another in which they are positively primed. We refer to the resulting treatments as NP-treatment and P-treatment, respectively. Before we conduct the experiment, participants were randomly allocated to each of these two treatments.

Our procedure of priming subjects follows a methodology commonly used in other psychological experiments (see, for instance, Bargh, et al, 2001). More 
specifically, the priming manipulation was carried out through an initial word-search puzzle that each participant completed by him/herself at the beginning of the experimental session. A $16 \times 16$ matrix of letters was presented, along with which there was a list of 20 words that were embedded in the matrix. Words could appear with letters in a straight line either from left to right or from right to left reading down or reading up, and diagonally reading either down or up. Each list contained the same set of 5 neutral words to be found (carpet, lamp, plant, shampoo, window), with the remaining 15 words being (or not) relevant to the concept of cooperation (depending on the treatment). In the P-treatment, these words were teamwork, assist, responsibility, participate, community, collaborate, mutual, united, share, collective, society, trust, harmony, contribute and support. ${ }^{3}$ In the NP-treatment, these words were butterfly, turtle, umbrella, salad, corkscrew, illustrate, hat, building, gasoline, river, ranch, mountain, cabbage, stapler and peach.

The instructions for the word-search puzzles informed participants that they would have a total of 10 minutes to find as many words as they could, but their total earnings from the experiment will not be affected by their performance in this task. At the end of the allotted time, the experimenter handed out to subjects the solutions of the word search puzzle, so that they are aware of the correct answers in order for everyone in the treatment group to be primed.

After subjects had completed the first task, subjects were given new instructions describing the second task which consisted of the linear public goods game, outlined in Section 2.1. ${ }^{4}$ The description of the second task was identical under both treatments. Subjects had to decide how many tokens of their initial endowment they were willing to contribute. After they make their contribution decisions, they were asked to state their beliefs about contributions of the other group members. It is worth noting that elicitation of beliefs was non-incentivised to avoid possible confounding effects with the elicitation of self-reported emotions.

\footnotetext{
${ }^{3}$ Selection of the positive priming words was based on a pre-test in which 50 words were judged with regards to their relatedness to cooperation. 28 pre-test participants were recruited in order to judge these 50 words and ratings were made on a 7-point scale ( 1 = "not at all", ., $7=$ "very much"). Pretest participants received a fixed payment of $£ 5$ for completing this task. The selected primes were those with the highest ratings. Appendix A provides the complete list of the 50 words used, along with their corresponding average scores.

${ }^{4}$ The instructions used for both tasks are given in Appendix B. As we wanted to ensure that subjects understood the decision situation, at the end of the experimental instructions all participants answered several test questions, concerning what the payoffs would be for various hypothetical configurations of behaviour.
} 
In an attempt to assess the impact of priming on non-behavioural indicators of perceptions of free-riding behaviour, we also elicited subjects' emotional responses. More specifically, subjects were asked at the end of the game in each treatment to indicate the intensity of positive and negative affect they felt about the actual contribution behaviour of each member of their group. For a similar process on eliciting self-reported emotional responses, see also Bosman and van Winden (2002) and Cubitt et al. (2008). In particular, subjects were given a list of 13 affective states, and were then asked to indicate the intensity with which they felt each emotion when they saw the contribution of each other group member. The intensity for each emotion was recorded on a 7-point scale $\left(1=\right.$ "not at all", .., 7 = "very much"). ${ }^{5}$ The list of the thirteen elicited affective states with the order presented to subjects is as follows: warmth, anger, fear, envy, sadness, happiness, shame, irritation, contempt, guilt, joy, jealousy and surprise - four being positive states, nine being negative states and one being neutral state.

In a de-briefing post-experimental questionnaire, we also asked the participants what they thought the experiment was about, so we can elicit the demand effect explanation.

A noteworthy aspect of our design is that participants played a one-shot linear public goods game under one of the treatments described above. The reason for choosing a one-shot interaction is that we wanted to investigate the pure effects of our priming process on subjects' cooperative behaviour and emotions, and thus, eliminate the confounding effects that might come from repeated interaction. Since the effects of priming on cooperative behaviour have not yet been explored, in this paper we are interested in identifying the existence of such effect and thus, why we chose a oneshot interaction among subjects. The persistence of such an effect with the repetition of the game is a separate issue and warrants further research.

In total, 51 subjects participated in the NP-treatment and 54 in the P-treatment. All subjects were recruited at the University of York, using the ORSEE software (Greiner, 2004). Their vast majority was undergraduate students from different academic fields. The experiment was conducted in the Centre for Experimental Economics (EXEC) lab and both treatments were computerised and programmed with the software z-Tree (Fischbacher, 2007). At the end of a session, subjects were

\footnotetext{
${ }^{5}$ Appendix $\mathrm{C}$ provides a screenshot of the interface we used for eliciting self-reports on emotions.
} 
privately paid according to their total amount of guilders from the one-shot linear public goods game, using an exchange rate of $£ 0.40$ per guilder. Average earnings per treatment were as follows: $£ 9$ for the NP-treatment and $£ 9.34$ for the P-treatment. Sessions lasted, on average, 50 minutes, with no session taking more than 60 minutes.

\subsection{Hypotheses}

Assuming subjects only care about their own earnings, the linear public goods game has a unique Nash equilibrium. As explained in Section 2.1, the cost of contributing one token to the project is less than the private return on that, and therefore, it is in any subject's material self-interest to keep always all one's own tokens. However, there is rich experimental evidence indicating that subjects diverge from these standard game theoretic predictions. In one-shot versions of the public goods game, participants on average contribute approximately $40 \%$ of their initial endowment of tokens. Relying on this established literature, we expect subjects to contribute to some extent to the public good both in the NP-treatment and the Ptreatment.

However, it is hard to derive a definite prediction of whether there should be a difference in behaviour between the NP-treatment and the P-treatment. For instance, although the inequity aversion model by Fehr and Schmidt (1999) or the model of equity, reciprocity and competition by Bolton and Ockenfels (2000) can explain contributions to the public good, these theories cannot account for any subtle effect inherent in the environment in which individuals interact, such as priming. Yet, motivated by existing experimental evidence, one can reason as follows to derive plausible hypotheses.

First, experimental findings from social psychology demonstrate that priming impacts on a wide range of individuals' attitudes and behaviours (e.g., see Bargh and Ferguson, 2000; Duckworth et al, 2002; Vohs et al, 2006; Bargh and Morsella, 2008). These findings suggest that individuals who have been primed in a positive way show enhanced pro-social behaviour, reporting higher levels of cooperation, relative to individuals who have been neutrally primed.

On the other hand, recent evidence from economic experiments has also indicated that characteristics of the environment that should have no effect on individuals' choices turn out to influence their actual behaviour. For instance, Altmann and Falk (2009) investigates the influence of non-binding default rules on 
voluntary cooperation. Their findings suggest that non-binding defaults particularly influence contribution decisions of participants with lower levels of cognitive reflection, whereas contributions of participants with high scores on a cognitive reflection test are virtually unaffected. In addition, Kirchsteiger et al. (2006) report an experiment showing that individuals in a good mood have higher levels of generosity in a gift-exchange game. Capra (2004) records strong effects of induced mood in a dictator game, where good-mood subjects were more helpful or altruistic, while Oswald et al. (2009) find that an exogenous shock in people's happiness increase their productivity levels in a paid task. As priming cooperation can act as a subconscious reminder for people to behave pro-socially, we expect individuals' propensity to cooperate to be higher in the P-treatment than in the NP-treatment. Thus, our first hypothesis suggests that subjects' contributions will be higher in the P-treatment than in the NP-treatment.

Second, as a complementary tool to investigate the role of priming, we elicited individuals' self-reported emotional responses. Recent experimental evidence demonstrates emotional responses to be closely related with observed experimental behaviour, with positive/negative emotions being connected with positive/negative concerns (Bosman and van Winden, 2002; Cubitt et al., 2008; Fehr and Gächter, 2000). Since positive priming generates positive concerns in the environment individuals interact, we expect them to respond emotionally in an analogous way.

To analyse emotions, we ask each individual to report their emotions after they have seen the other players' contributions. For instance, player $\mathrm{i}$ is asked to report how happy they are with players $\mathrm{j}$ and $\mathrm{k}$ after they have seen what players $\mathrm{j}$ and $\mathrm{k}$ contribute, which gives us two emotions data points for each player in the group. ${ }^{6}$ For our analysis, we use the "emotions' function", which gives aggregate emotions in a given category (either positive or negative) as a function of deviations of players $j$ 's contributions from player i's own contribution. For instance, the mean positive emotions' function plots mean positive emotions as a function of deviations of players j's contributions from player i's contribution. We expect the "emotions' function" to be negatively sloped in the negative deviation interval (i.e. when players $\mathrm{j}$ contributes less than player i) for the negative emotions, and positively sloped in the negative deviation interval for the positive emotions. We hypothesise that, within the range of

\footnotetext{
${ }^{6} \mathrm{We}$ refer to player $\mathrm{i}$ as the individual who express his/her emotion, player $\mathrm{j}$ as the comparison partner and player $\mathrm{k}$ as the non-comparison partner.
} 
the positive deviation interval (i.e. when players $\mathrm{j}$ contribute more than player $\mathrm{i}$ ), for the negative emotions the function will be negatively sloped; whereas, for the positive emotions, it will be positively sloped. Motivated by our first hypothesis, our expectation is that, with respect to priming, the emotions' function will move or be tilted upwards with regards to positive emotions; and downwards with regards to negative emotions.

\section{Results}

\subsection{Levels of contributions}

Does positive priming lead people to contribute more? Figure 1 provides a first pass at this question by presenting the distribution of contributions across participants in the two groups. ${ }^{7}$ Three interesting patterns emerge. First, in both treatments contributions of either 0 or 10 tokens are the modal contribution levels. Specifically, $45 \%$ of the subjects in the NP-treatment and $37 \%$ of the subjects in the P-treatment completely free ride, whereas the percentage of those who contribute 10 tokens is quite similar in both treatments $(22 \%$ in the NP-treatment and $20 \%$ of the subjects in the P-treatment). Second, complete co-operators (that is, subjects who contribute their total endowment) appear only in the P-treatment (13\%), while none of the subjects in the NP-treatment contribute 20 tokens. Third, as for the other levels of contributions, they seem to be fairly widely spread across both treatments. Performing a Kolmogorov-Smirnov test, we find no significant differences between the treatments $(\mathrm{p}$-value $=0.552)$.

We reach the same conclusion when we consider the average contributions. Here, average contributions were 5 tokens in the NP-treatment, with a standard error of $0.773(\mathrm{~N}=51)$, and 6.89 tokens in the P-treatment, with a standard error of 0.932 $(\mathrm{N}=54)$. A non-parametric ranksum Wilcoxon test suggests that average contribution levels are not significantly different, irrespective of the presence of priming (twosided test; $\mathrm{p}$-value $=0.249$ ).

The statistical indifference in the raw averages of contribution between the treated and the non-treated groups may be due to the unaccounted characteristics of the participants, such as gender, field of studies and possibly nationality, so we

\footnotetext{
${ }^{7}$ At the end of the experiment, we asked individuals to write down what they thought the experiment was about. Several individuals suggested that the word search made them think more cooperatively. So to control for this, we have taken out these individuals and the following results remain the same. Therefore, the prime here is separate to induced demand effects.
} 
control for these in Table 1. This Table presents OLS estimates of the priming effect on contribution with no controls. Column 1's regression reproduces Figure 1's results: the P-group contributed 1.889 more than the NP-group, though the difference between the two groups is not statistically significant at conventional levels. Column 2 adds a control on the participants' gender. Here, we can see that the coefficient on priming increases from 1.889 to 2.104 , and it is significant at the $10 \%$ level. Similarly, the female coefficient is 2.375 , with a well-determined standard error at the $10 \%$ level of 1.225. This is consistent with previous studies on public good games (e.g., Nowell and Tinkler, 1994), which find evidence of women being more generous and tending to contribute more, on average, compared to men. Because females contribute more on average compared to males and that there are proportionately more females $(52.5 \%$ of all female subjects; $\mathrm{N}=61$ ) in the NP-group compared to males in the NP-group (43.2\% of all male subjects; $\mathrm{N}=44$ ), it partly explains why there is an insignificant raw data difference in the level of contributions between the P-group and the NPgroup.

One question of interest would be whether women are more sensitive to priming compared to their male counterpart. Croson and Gneezy (2009) review the literature and find significant differences in social preferences for men and women. Whilst there is evidence suggesting a significant difference in the average contribution levels between male and female participants, little is known whether men and women are both equally susceptible to methods that activate their implicit memories, such as priming for example. Column 3 tests this hypothesis by dividing the sample into four groups: Male neutrally-primed $(\mathrm{N}=19)$; Male positively primed $(\mathrm{N}=25)$; Female neutrally-primed $(\mathrm{N}=32)$; and Female positively primed $(\mathrm{N}=29)$. With "Male neutrally-primed" as the reference category, we can see that the group which contributed the highest amounts was the "Female positively primed" group; the coefficient on "Female positively primed" group is 4.165 , with a statistically welldetermined standard error at the 5\% level of 1.777 . Both "Female neutrally-primed" and "Male positively primed" contributed more of their endowments, on average, than "Male neutrally-primed". Yet the differences in the coefficients are not statistically significantly different from each other. By contrast, we can reject the null hypothesis at the $5 \%$ level that "Female positively primed" is the same across all categories, i.e. "Male neutrally-primed" (p-value $=0.0211)$, "Male positively-primed" $(\mathrm{p}$-value $=$ 0.0461 ), and "Female neutrally-primed" ( $p$-value $=0.0443$ ). The raw differences 
between the "Female positively primed" and other categories are so striking that it also shows up very clearly on a diagram; see Figure 2.

This result implies that females are significantly more susceptible to priming compared to males, i.e. positively primed females contribute roughly 3.25 tokens more than the neutrally primed females. By contrast, priming seems to have an insignificant effect on the male sample. This is reflected in the constant slope in terms of male contribution across the NP and P groups.

Columns 4 and 5 replicate the previous two columns, but adding standard controls on the participants' field of study and nationality. Controlling for fields of study and nationalities yields similar coefficients on priming as the ones obtained in Column 3. We observe that there is little evidence that economics students contribute significantly different compared to non-economics students and that there is also no statistical difference in terms of contribution between UK students and non-UK students. Yet, the gender difference in contribution behaviour even after adding these variables remains robust. ${ }^{8}$

\subsection{The role of beliefs}

We next analyse how priming impacts on beliefs about other group members' contributions. As a first step, we examine how contributions and beliefs about contributions are correlated for each of our two treatments separately. This is illustrated in Figure 3, in which contributions are plotted as a function of beliefs about contributions. Circles represent combinations of contributions and beliefs about contributions per treatment, with the size of the circles being proportional to the number of observations. Circles on the horizontal axis correspond to zero contributions; whereas, circles on the diagonal axis indicate contributions that exactly match beliefs.

Not surprisingly, and in line with earlier evidence (see Dufwenberg et al, 2006), we observe that there is a positive relationship between contributions and beliefs about contributions in each treatment (see Figure 3). The Spearman correlation coefficients (NP-treatment: $\rho=0.572$ and P-treatment: $\rho=0.6734$ ) suggest that contributions and beliefs are positively and significantly correlated (in each treatment

\footnotetext{
${ }^{8}$ In particular, the coefficient "Female positively primed" is significantly different from the coefficient "Male positively primed" ( $\mathrm{p}$-value $=0.0644)$. This is also the case regarding the coefficients of "Female positively primed" and "Female neutrally primed" $(0.0445)$.
} 
p-values $=0.000$ ), with the priming treatment indicating a slightly higher correlation between contributions and beliefs.

Looking at average levels of beliefs about contributions, we find no significant differences (two-sided test; $\mathrm{p}$-value $=0.2718$ ) performing a non-parametric ranksum Wilcoxon test. Yet, recall from our analysis in the previous section that our priming technique has a significant impact on contribution behaviour controlling for subjects' gender. More specifically, we found that females are significantly more susceptible to priming compared to males, whereas, priming seems to have an insignificant effect on the male sample. Here, we investigate whether a parallel finding holds with respect to beliefs about others' contributions. In other words, do female primed subjects believe that their group members will contribute more compared to male primed subjects? Figure 4, which plots beliefs about contribution in each of our four groups previously defined, provides an affirmative answer to this question. In particular, we find that primed females believe that the other two group members will contribute, on average, 9.52 tokens, while primed males report a value of average beliefs equal to 6.44 tokens. This difference is significant at 5\% level (ranksum Wilcoxon test; two-sided test; $\mathrm{p}$-value $=0.0351)$. In addition, in the P-treatment, we also find that females believe that others will contribute significantly more relative to females in the NPtreatment (ranksum Wilcoxon; test two-sided test; p-value $=0.0212$ ). However, looking only at the male sample, we find no significant differences across treatments (ranksum Wilcoxon test; two-sided test; $\mathrm{p}$-value $=0.3760$ ).

Table 2 provides econometric evidence supporting Figure 4. Using OLS regressions, Column 1 suggests that the observed gender difference in contributions can be explained through a difference in beliefs about others' contributions. Here, we see that the coefficient of the dummy variable "Female positively primed" is significantly different from that of the variable "Male positively primed" ( $\mathrm{p}$-value $=$ $0.0202)$ and "Female neutrally primed" (p-value $=0.0179) .{ }^{9}$

Thus far, our main finding suggests that priming affects people's contribution behaviour and beliefs about contributions, after controlling for their gender, with females being more susceptible to priming than males. More specifically, the way

\footnotetext{
9 Adding further controls, such as field of study and nationality, our differences between the coefficients of "Female positively primed" and "Male positively primed", and between the coefficients of "Female positively primed" and "Female neutrally primed" with respect to self-reports of beliefs about contributions remain significant with p-values being 0.0212 and 0.0182 , respectively (see Column 3 of Table 2 for econometric evidence).
} 
priming works in our subject pool is in two steps: first, positive primes shift females' beliefs about the contributions of the other counterparts and then, these beliefs shape their motivation and contribution decisions.

Our next step is to determine whether the shift in contribution behaviour caused by priming is linked to subjects' self reported emotional responses.

\subsection{Self-reported emotions}

We investigate how people respond to priming by exploring their self-reported emotions after contribution levels of the other two group members have been revealed. Other than playing a key role in the social preferences literature, emotions are interesting in our context because priming has been shown in the psychological literature to have a significant impact on individuals' emotions, especially positive emotions (see, e.g., Williams and Bargh, 2008).

Recall that, in total, we elicited 13 affective states, with positive states comprising warmth, happiness and joy; whereas, negative states comprising anger, fear, envy, sadness, shame, irritation, contempt, guilt and jealousy. As a first step to identify whether priming had an effect on individuals' emotional responses, Figures 5 and 6 plot, using raw data, mean positive and mean negative emotions as a function of the difference between contribution of player $j$ and the contribution of player $i$. The horizontal axis indicates the deviation of player j's contribution from player i's contribution, while the vertical axis indicates for each emotion the intensity (ranging from $1=$ "not at all" to 7 = "very much") with which a group member felt each emotion when they saw the contribution of the other group member. In both figures, each dot represents a single observation and the solid line indicates the fitted line of the locally weighted regression of emotions expressed on the deviation from the player i's contribution.

Looking at Figure 5, we can see that a positive relationship between the deviations of player's $\mathrm{j}$ contributions from player i's contribution and average positive affect, which is more evident for the people in the primed group. By contrast, Figure 6 obtains almost no difference in the relationship between the deviations from player i's contribution and average negative affect across the non-treated and treated groups. In sum, what these two graphs seem to suggest is that the priming effect is more pronounced in the case of positive emotions relative to negative emotions. 
Table 3 provides some descriptive statistics of the average positive and negative emotions expressed by subjects depending on how the comparison partner's (player j's) contribution has deviated from the own contribution. Here, we observe that average positive emotions between the NP-treatment and the P-treatment are significantly different with respect to non-negative deviations ( $\mathrm{p}$-value $=0.000$ ), but not with respect to negative deviations $(\mathrm{p}$-value $=0.691$ ). However, the same cannot be said for the negative emotions, where their mean levels are very similar both regarding non-negative $(p=0.327)$ and negative deviations $(p=0.110)$ from player i's contribution.

To formally examine the impact of priming on emotional responses, we control econometrically for key factors of the contribution behaviour, which may explain self-reports of emotions such as deviations from other players (see Table 4). To test whether the positive and negative emotions' function differs across treatments, we estimated ordered probit model for the average positive and negative emotions separately. So our dependent variables are the average of each of the positive and negative emotions to player $\mathrm{j}$ respectively. These emotional responses are ordered from 1 ("not at all") to 7 ("very much"). The independent variables comprise "Player j's absolute negative (contribution) deviation", "Player j's positive (contribution) deviation", "Player k's contribution deviation", and the dummy variable "Priming", which takes on the value ' 1 ' for the P-treatment and ' 0 ' for the NP-treatment. We also included two interaction terms, which indicate whether the slope of the emotions function differs with respect to negative and positive deviations across our treatments. We include "absolute negative deviation" and "positive deviation" as separate regressors, since Figure 5 and 6 suggests that these two different sorts of deviation elicit different emotional responses. The variable "absolute negative deviation" is the absolute value of the actual deviation of player $\mathrm{j}$ 's contribution from player i's contribution, when player j's contribution is below player i's contribution; and zero otherwise. The variable "positive deviation" is constructed in an analogous way. The variable "Player k's contribution deviation" is the actual deviation of player k's contribution from player i's contribution. The reason for including such a variable is that player i's attitude to player $\mathrm{j}$ may differ according to the behaviour of player $\mathrm{k}$.

It is clear from Table 5 that priming has an effect on the mean positive emotions, but not on the mean negative emotions, as suggested by Figures 5 and 6 . More specifically, we find that this difference is reflected on the slope of the mean 
positive emotions' function, which appears to be steeper with regards to the nonnegative deviation interval (i.e. when player $\mathrm{j}$ contributes more than or equal to player i) in the primed treatment compared to the non-primed treatment. By contrast, the dummy variable "Priming" and its interaction are statistically insignificant both with respect to the positive and the non-negative deviation intervals. ${ }^{10}$

\section{Conclusions}

This paper reports an experiment on the impact that priming has on individuals' subsequent decision making in a one-shot social dilemma game. Motivated by previous findings indicating that elements of the choice environment affect people's pro-social behaviour and that preferences have a psychological aspect to them, we study the effects of positive priming both on behavioural and nonbehavioural measures of reciprocity. Specifically, our concern is with how priming influences individual's cooperation rates and self-reported beliefs and emotional responses. Our findings suggest that, priming is effective in raising contribution levels and leads to more socially efficient outcomes compared to an environment where priming is absent, controlling for subjects' exogenous characteristics, such as gender. Females are found to be more susceptible to our priming technique compared to males and this difference can be explained due to a move to their expectations about how much other group members will contribute. We also find a link between priming and emotions, with the effect being more pronounced in mean positive emotions.

A noteworthy aspect of our findings is the observed difference in contributions between males and females. This is in agreement with the explanation suggested by Croson and Gneezy (2009) that women's behaviour is more context dependent than that of men (see also Gilligan (1982)). Specifically, in our setting, we explain our findings following Eckel and Grossman's (1998) distinction, in which gender differences emerge conditional on the level of risk present in the experiment (see also Croson and Buchan, 1999). In the presence of priming, the level of risk is arguably lower compared to the non-priming case, as in the former case primes can be regarded as a device in which subjects can coordinate. For instance, it could be that subjects regard primes as anchors or focal points, inducing them to coordinate on more

\footnotetext{
${ }^{10}$ Our observation that priming impacts significantly on the slope of the mean positive emotions' function and not on that of the mean negative emotions' function is robust after we control for subjects' gender.
} 
cooperative outcomes. As a result, primes reduce the level of risk incorporated in the decision situation and women tend to be more generous and pro-social in their behaviour.

Our result may also be due to the nature of the prime, in that women tend to be better at 'verbal' tasks than men (Mozley et al, 2001), and this is related to statements that women tend to use more their left 'verbal' brain hemisphere while men use more their right brains (see, for instance, Gur et al, 2000). In this respect, an interesting further research avenue is to use images as primes and see whether there is still any gender difference (and whether it goes in the opposite direction).

Like all studies in social science, this study is not without limitations. For example, we can say nothing about the long-term impacts of priming on repeated behaviours, as well as its general applicability on economically-related behaviours other than those observed in public good games. Notwithstanding this, we see our findings as an important tool at the hands of policy makers. Specifically, our research can have two potential policy implications. Firstly, priming could be used for solving collective action problems, such as goods like the commons. Many economic and social interactions in real life are envisioned by social-dilemma-type situations that require techniques, such as priming, to achieve specific behavioural goals that enhance social welfare. In addition, changing the language used in the media, education and health promotions, and in public/private organisations, can prime people to behave for the social goods.

Secondly, priming could be a useful tool for the government when designing educational and health policies, as well as environmental friendly campaigns. It is potentially a viable lever for policy-makers to change behaviour (Vlaev and Dolan, 2009), but economics needs to understand further when priming works well and when it does not work so well. Further research could determine alternative primes for reciprocity as well as examine the individual versus group nature of such a prime. For instance, recent experimental studies (e.g., Luchan, et al., in press) find that groups of people are typically less altruistic or cooperative than individuals. It would be interesting to determine whether priming can influence decisions at a group level to the same extent at individual level. In addition, it is important to examine how long such primes last, and whether it prevents the well-documented decay effect of contributions over repeated interactions. 
Future studies should also try to examine to distinguish between the two explanations that the prime may make me more co-operative and/or make me think that others will be. It would be of interest to know the relative weight of each explanation. 
Figure 1: Distribution of contributions by treatment

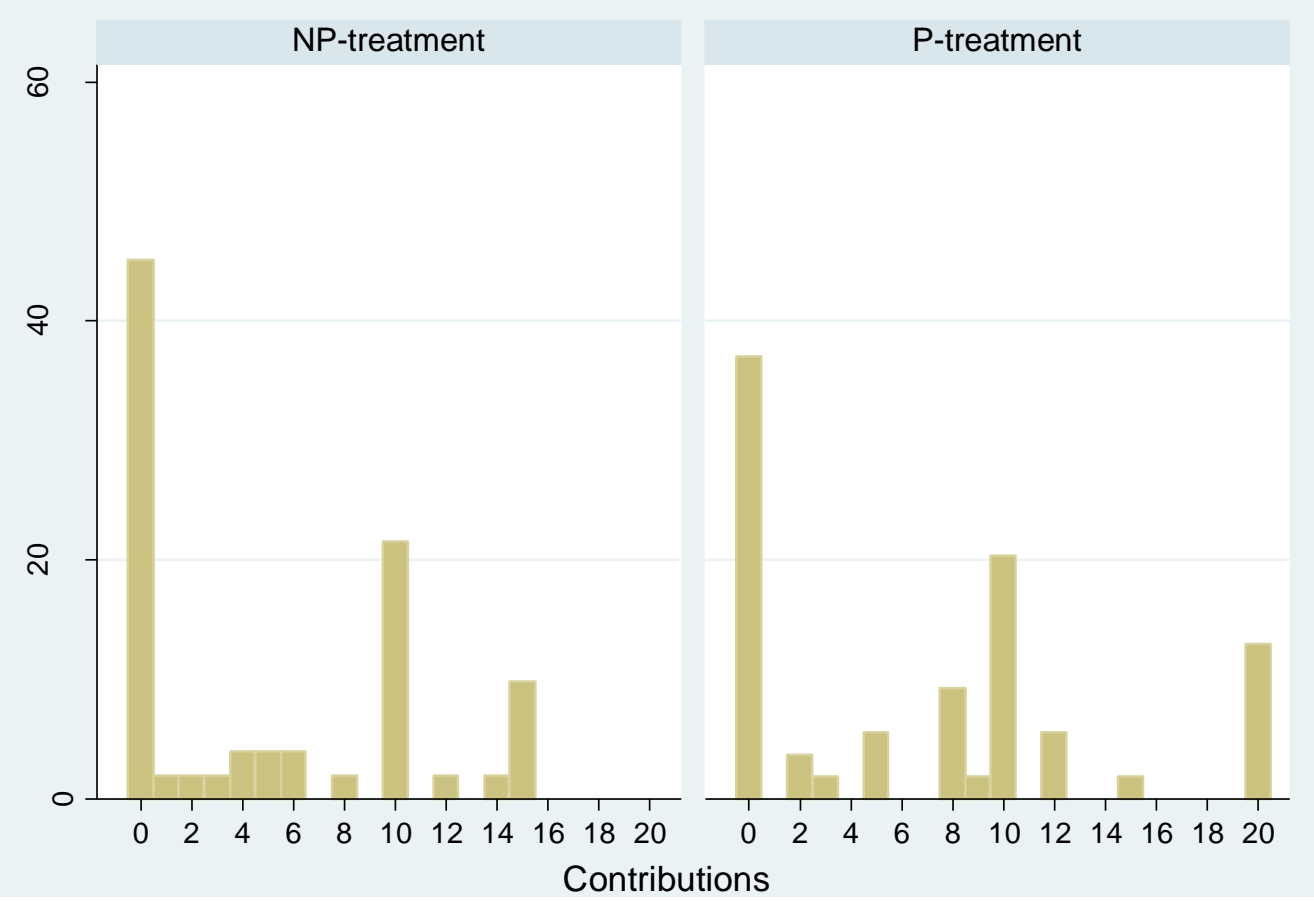


Table 1: OLS Regressions on the Effect of Priming on the Level of Contributions

Dependent variable: Level of contributions

\begin{tabular}{|c|c|c|c|c|c|}
\hline & (1) & (2) & (3) & (4) & (5) \\
\hline $\begin{array}{l}\text { Positive } \\
\text { priming }\end{array}$ & $\begin{array}{c}1.889 \\
(1.211)\end{array}$ & $\begin{array}{l}2.104+ \\
(1.202)\end{array}$ & & $\begin{array}{l}2.142+ \\
(1.210)\end{array}$ & \\
\hline Female & & $\begin{array}{l}2.376+ \\
(1.225)\end{array}$ & & $\begin{array}{l}2.319+ \\
(1.302)\end{array}$ & \\
\hline $\begin{array}{l}\text { Male: } \\
\text { positively } \\
\text { primed }\end{array}$ & & & $\begin{array}{c}0.499 \\
(1.825)\end{array}$ & & $\begin{array}{c}0.640 \\
(1.897)\end{array}$ \\
\hline $\begin{array}{l}\text { Female: } \\
\text { neutrally } \\
\text { primed }\end{array}$ & & & $\begin{array}{c}0.923 \\
(1.603)\end{array}$ & & $\begin{array}{c}0.999 \\
(1.679)\end{array}$ \\
\hline $\begin{array}{l}\text { Female: } \\
\text { positively } \\
\text { primed }\end{array}$ & & & $\begin{array}{l}4.165^{*} \\
(1.778)\end{array}$ & & $\begin{array}{l}4.209^{*} \\
(1.872)\end{array}$ \\
\hline $\begin{array}{l}\text { Nationality: } \\
\text { UK }\end{array}$ & & & & $\begin{array}{l}-1.169 \\
(1.185)\end{array}$ & $\begin{array}{l}-1.008 \\
(1.183)\end{array}$ \\
\hline $\begin{array}{l}\text { Economics } \\
\text { students }\end{array}$ & & & & $\begin{array}{c}0.649 \\
(1.376)\end{array}$ & $\begin{array}{c}0.736 \\
(1.384)\end{array}$ \\
\hline Constant & $\begin{array}{c}5.000 * * \\
(0.772)\end{array}$ & $\begin{array}{l}3.509 * * \\
(1.094)\end{array}$ & $\begin{array}{c}4.421 * * \\
(1.264)\end{array}$ & $\begin{array}{c}3.924 * * \\
(1.471)\end{array}$ & $\begin{array}{l}4.642 * * \\
(1.584)\end{array}$ \\
\hline R-squared & 0.0228 & 0.0577 & 0.0693 & 0.0694 & 0.0794 \\
\hline Observations & 105 & 105 & 105 & 105 & 105 \\
\hline
\end{tabular}


Figure 2: Contributions by gender and treatment

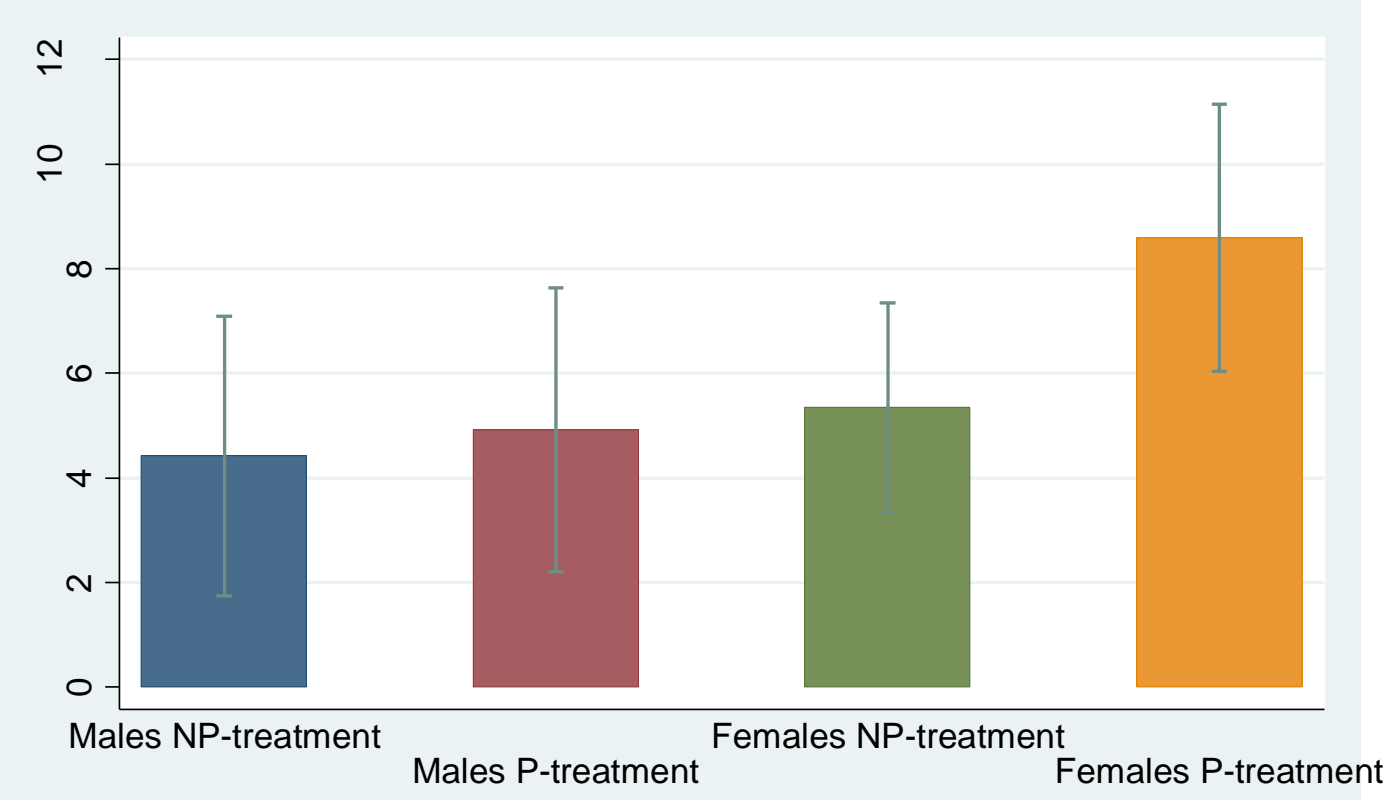

Note: Males neutrally-primed $(N=19) ;$ Males positively-primed $(N=25) ;$ Females neutrally-primed $(N=32) ;$ Females positively-primed $(N=29)$. 95\% confidence intervals in each category are also shown. 
Figure 3: Contributions as a function of beliefs about contributions per treatment
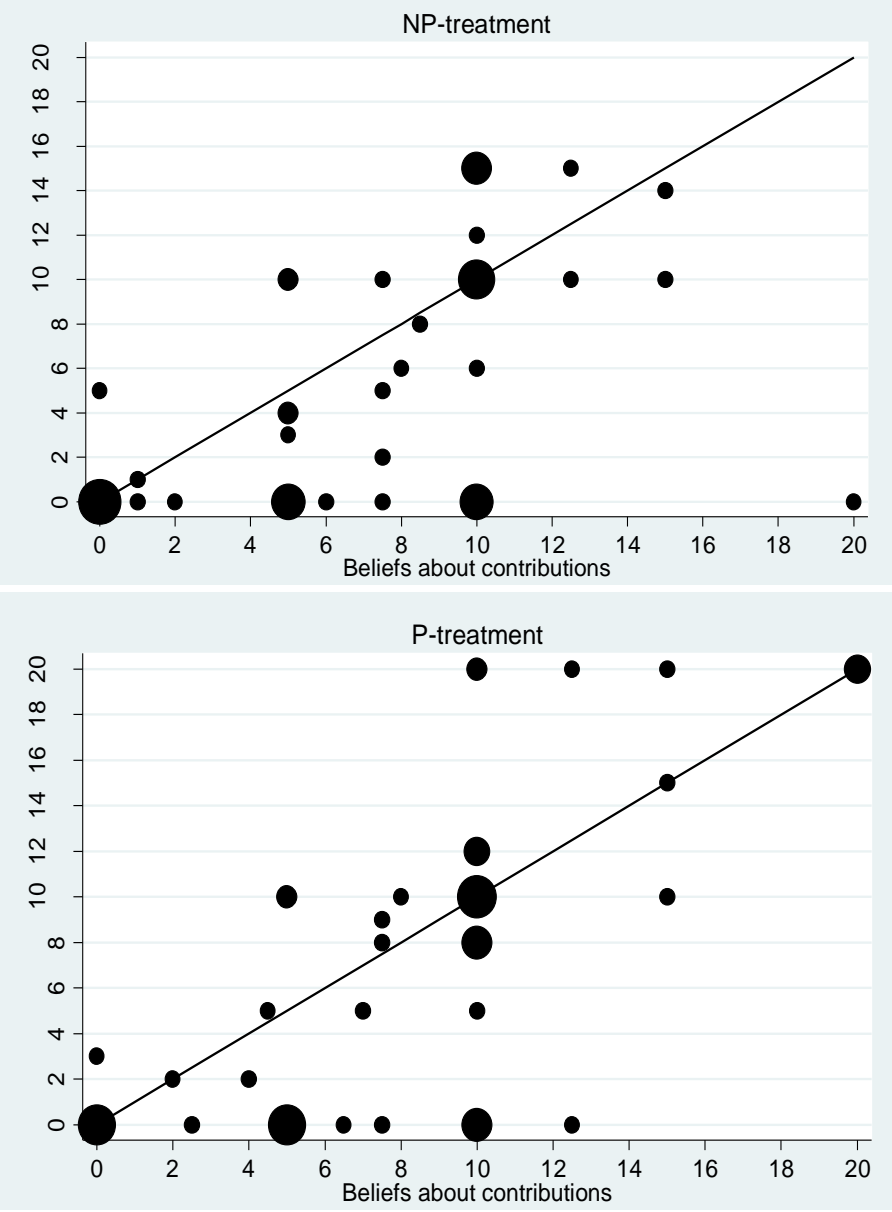
Figure 4: Beliefs about contributions by gender and treatment

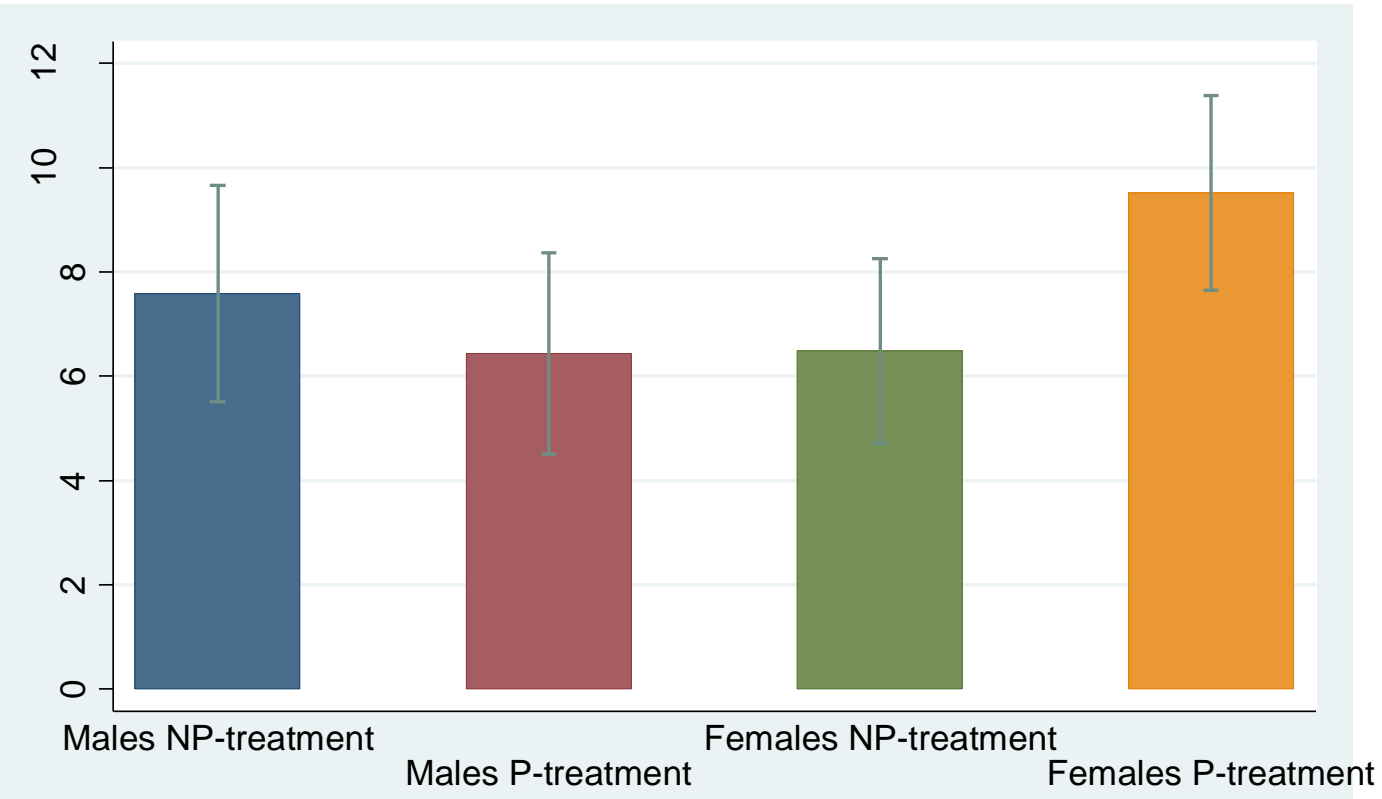


Table 2: OLS Regressions on the Effect of Priming on Beliefs about Contributions Dependent variable: Beliefs about contributions

(1)

(2)

\begin{tabular}{lcc}
\hline $\begin{array}{l}\text { Positive } \\
\text { priming }\end{array}$ & & \\
\hline Female & -1.139 & -1.038 \\
\hline Male: & $(1.353)$ & $(1.378)$ \\
positively & & \\
primed & -1.095 & -1.015 \\
Female: & $(1.310)$ & $(1.350)$ \\
neutrally & & \\
\hline primed & 1.938 & 2.006 \\
Female: & $(1.338)$ & $(1.387)$ \\
primed & & -0.747 \\
\hline Nationality: & & $(0.901)$ \\
UK & & 0.707 \\
Economics & & $(1.055)$ \\
students & $7.579 * *$ & $7.674 * *$ \\
\hline Constant & $(0.980)$ & $(1.205)$ \\
\hline R-squared & 0.0731 & 0.0845 \\
Observations & 105 & 105 \\
\hline Note: $* *<1 \%$. Robust standard errors are presented in parentheses. "Male neutrally primed" is the \\
reference category.
\end{tabular}


Figure 5: Mean positive emotions by treatment

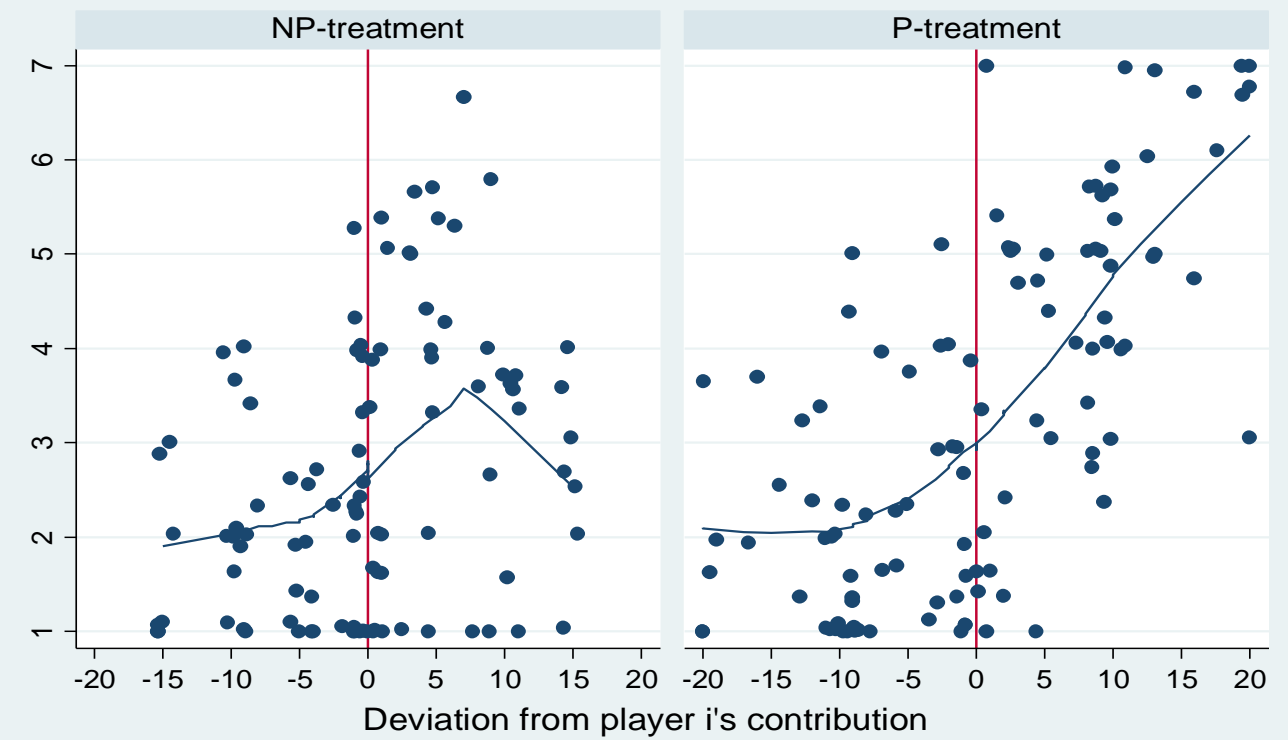


Figure 6: Mean negative emotions by treatment

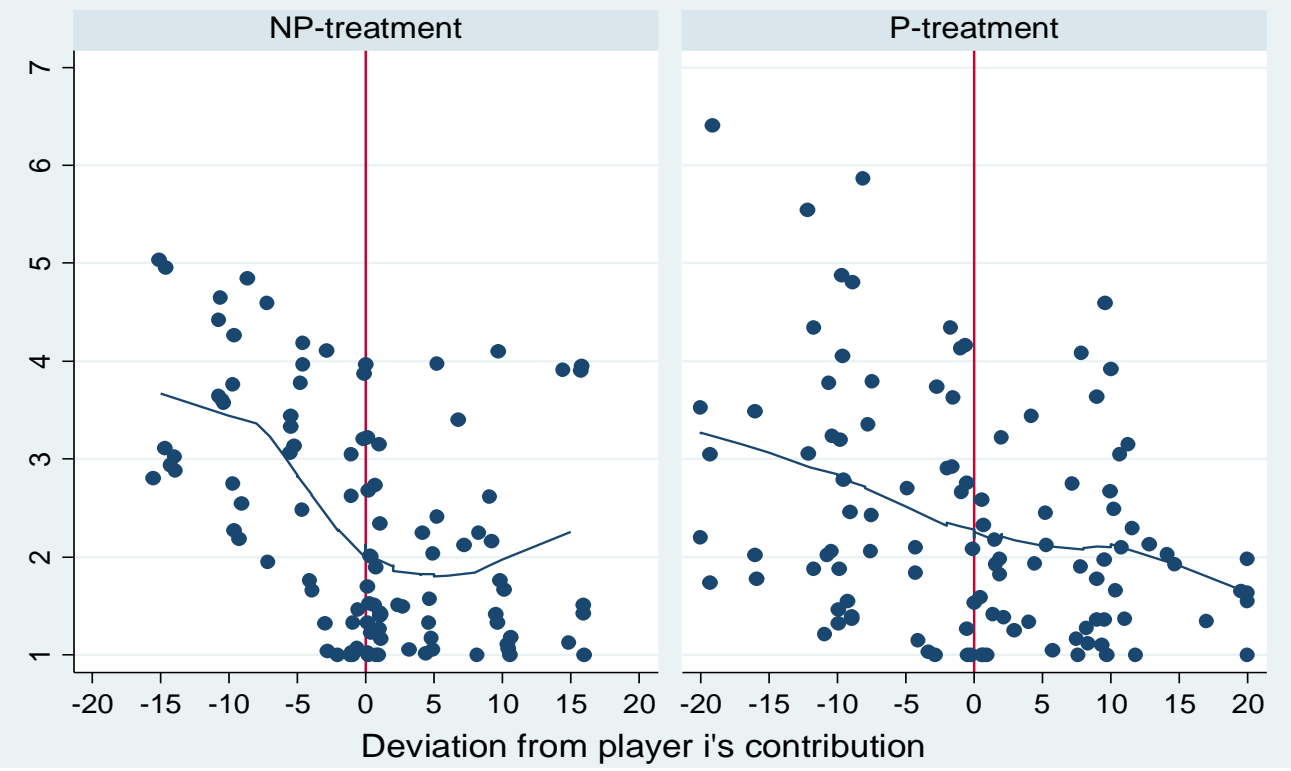


Table 3: Some descriptive statistics of mean positive emotions and negative emotions

\begin{tabular}{llc}
\hline \hline & \multicolumn{2}{c}{ Mean positive emotions } \\
\cline { 2 - 3 } Negative deviations & NP-treatment & P-treatment \\
Non-negative deviations & $2.102(1.138)$ & $2.203(1.189)$ \\
& \multicolumn{2}{c}{ Mean negative emotions } \\
\cline { 2 - 3 } Negative deviations & NP-treatment & P-treatment \\
Non-negative deviations & $3.203(1.087)$ & $2.853(1.303)$ \\
\hline \hline
\end{tabular}

Note: 1 = "not at all"; 7 = "very much". Entries are means and standard deviations. 
Table 4: Ordered Probit Regressions on the Effect of Priming on Mean Positive and Mean Negative Emotions

Dependent variable: Mean positive emotions

\begin{tabular}{|c|c|c|c|c|}
\hline & \multicolumn{2}{|c|}{$\begin{array}{l}\text { Dependent variable: Mean } \\
\text { positive emotions }\end{array}$} & \multicolumn{2}{|c|}{$\begin{array}{c}\text { Dependent variable: Mean } \\
\text { negative emotions }\end{array}$} \\
\hline & $\begin{array}{c}\text { Non- } \\
\text { negative } \\
\text { Deviations }\end{array}$ & $\begin{array}{l}\text { Negative } \\
\text { Deviations }\end{array}$ & $\begin{array}{c}\text { Non- } \\
\text { negative } \\
\text { Deviations }\end{array}$ & $\begin{array}{l}\text { Negative } \\
\text { Deviations }\end{array}$ \\
\hline $\begin{array}{l}\text { Player } j \text { 's } \\
\text { absolute negative } \\
\text { deviation from } \\
\text { player } i \text { 's } \\
\text { contribution }\end{array}$ & & $\begin{array}{c}-0.095+ \\
(0.055)\end{array}$ & & $\begin{array}{c}0.111 * * \\
(0.041)\end{array}$ \\
\hline $\begin{array}{l}\text { Player } j \text { 's } \\
\text { positive deviation } \\
\text { from player } i \text { 's } \\
\text { contribution }\end{array}$ & $\begin{array}{c}0.025 \\
(0.021)\end{array}$ & & $\begin{array}{c}0.019 \\
(0.028)\end{array}$ & \\
\hline $\begin{array}{l}\text { Player } k \text { 's } \\
\text { contribution } \\
\text { deviation from } \\
\text { player } i \text { 's } \\
\text { contribution }\end{array}$ & $\begin{array}{l}-0.025+ \\
(0.014)\end{array}$ & $\begin{array}{c}-0.043 * * \\
(0.014)\end{array}$ & $\begin{array}{c}0.004 \\
(0.013)\end{array}$ & $\begin{array}{c}0.017 \\
(0.014)\end{array}$ \\
\hline Positive priming & $\begin{array}{l}-0.172 \\
(0.298)\end{array}$ & $\begin{array}{l}-0.208 \\
(0.571)\end{array}$ & $\begin{array}{c}0.248 \\
(0.278)\end{array}$ & $\begin{array}{c}0.288 \\
(0.513)\end{array}$ \\
\hline $\begin{array}{l}\text { Priming } \times \text { Player } \\
j \text { 's absolute } \\
\text { negative } \\
\text { deviation from } \\
\text { player } i \text { 's } \\
\text { contribution }\end{array}$ & & $\begin{array}{c}0.046 \\
(0.061)\end{array}$ & & $\begin{array}{l}-0.077 \\
(0.051)\end{array}$ \\
\hline $\begin{array}{l}\text { Priming } \times \text { Player } \\
j \text { 's positive } \\
\text { deviation from } \\
\text { player } i \text { 's } \\
\text { contribution }\end{array}$ & $\begin{array}{c}0.131 * * \\
(0.042)\end{array}$ & & $\begin{array}{l}-0.017 \\
(0.038)\end{array}$ & \\
\hline Observations & 127 & 83 & 127 & 83 \\
\hline
\end{tabular}

Dependent variable: Mean negative emotions

Notes: + <10\%; **<1\%. Robust standard errors are presented in parentheses. As mentioned in the text, player $k$ is always the no-comparison partner of player $i$. 


\section{References}

Altmann, S., and Falk, A. 2009. The Impact of Cooperation Defaults on Voluntary Contributions to Public Goods. Mimeo.

Andreoni, J. 1995. Warm-Glow versus Cold-Prickle: The Effects of Positive and Negative Framing on Cooperation in Experiments.' Quarterly Journal of Economics, 110: 1-21

Ariely, D., Loewenstein, G. and Prelec, D. 2003. "Coherent Arbitrariness": Stable Demand Curves Without Stable Preferences. Quarterly Journal of Economics, 118: 73-105.

Bargh, J.A. and Ferguson, M.J. 2000. Beyond Behaviorism: On the Automaticity of Higher Mental Processes. Psychological Bulletin, 126: 925-945.

Bargh, J., A., Gollwitzer, P., M., Lee-Chai, A., Barndollar, K., and Trötschel, R., 2001. The Automated Will: Nonconscious Activation and Pursuit of Behavioural Goals. Journal of Personality and Social Psychology 81, 10141027.

Bargh, J.A., \& Morsella, E. 2008. The unconscious mind. Perspectives on Psychological Science, 3, 73-79.

Bochet, O., T. Page and L. Putterman, 2006. Communication and Punishment in Voluntary Contribution Experiments. Journal of Economic Behavior and Organization 60, 11-26.

Bolton, G., and Ockenfels, A, 2000. ERC: A theory of Equity, Reciprocity, and Competition. American Economic Review 90, 166-193.

Bosman, R., and van Winden, F., 2002. Emotional Hazard in a Power-to-Take Experiment, Economic Journal 112, 147-169.

Bosman, R., and Winden, F., forthcoming. Global Risk, Investment, and Emotions, Economica.

Capra, M., 2004. Mood-Driven Behavior in Strategic Interactions, American Economic Review 94, 367-372, Papers and Proceedings of the One Hundred Sixteenth Annual Meeting of the American Economic Association.

Croson R., and Buchan N., 1999, Gender and Culture: International Experimental Evidence from Trust Games, American Economic Review 89, 386-391.

Croson, R., and Gneezy, U., 2009, Gender Differences in Preferences, Journal of Economic Literature 47, 448-474.

Cubitt, R., Drouvelis, M., \& Gächter, S., 2008, Framing and free riding: emotional responses and punishment in social dilemma games. CeDEx Discussion Paper No. 2008-02, University of Nottingham.

DellaVigna, S. 2009. Psychology and Economics: Evidence from the Field. Journal of Economic Literature, 47: 315-372.

Duckworth, K.L., Bargh, J.A., Garcia, M., \& Chaiken, S. 2002. The automatic evaluation of novel stimuli. Psychological Science, 6, 515-519.

Dufwenberg, M., Gächter, S., and Hennig-Schmidt, H. 2006. The Framing of Games and the Psychology of Strategic Choice. CeDEx Discussion Paper No. 200620 .

Eckel, C., and Grossman, P., 1998, Are Women Less Selfish Than Men?: Evidence from Dictator Experiments, Economic Journal 108, 726-735.

Fehr, E. and Fischbacher, U. 2002. Why Social Preferences Matter - The Impact of Nonselfish Motives on Competition, Cooperation, and Incentives. Economic Journal, 112, C1-C33. 
Fehr, E. and Gächter, S., 2000, Cooperation and Punishment in Public Goods Experiments. American Economic Review 90, 980-994.

Fehr, E., and Gächter, S., 2002, Altruistic Punishment in Humans, Nature 415, 137 140.

Fehr, E., and Schmidt, K., 1999. A Theory of Fairness, Competition and Cooperation. Quarterly Journal of Economics 114, 817-868.

Fischbacher, U. 2007. z-Tree: Zurich Toolbox for Ready-made Economic Experiments. Experimental Economics, 10, 171-178.

Gilligan, Carol. 1982. "In a Different Voice: Psychological Theory and Women's Development," Harvard University Press: Cambridge, MA.

Greiner, B., 2004. 'An Online Recruitment System for Economic Experiments', In: Kurt Kremer and Volker Macho (Eds.): Forschung und wissenschaftliches Rechnen 2003, GWDG Bericht 63. Göttingen: Gesellschaft für Wissenschaftliche Datenverarbeitung, pp. 79-93.

Gur, R.C., Alsop, D., Glahn, D., Petty, R., Swanson, C.L., Maldjian, J.A., Turetsky, B.I., Detre, J.A., Gee, J., Gur, R.E., 2000. An fMRI study of sex differences in regional activation to a verbal and a spatial task. Brain and Language, 74,157170.

Güth, W., Levati, M. V., Sutter, M., Van der Heijden, E., 2007. Leading by example with and without exclusion power in voluntary contribution experiments. Journal of Public Economics, 91, 1023-1042.

Hertel, G., \& Fiedler, K., 1994. Affective and cognitive influences in a social dilemma game. European Journal of Social Psychology 24, 131-145.

Hertel, G., \& Fiedler, K., 1998, Fair and dependent versus egoistic and free: effects of semantic and evaluative priming on the 'Ring Measure of Social Values'. European Journal of Social Psychology 28, pp. 49-70.

Isaac, M., and J. Walker 1988. Communication and Free-Riding Behaviour: The Voluntary Contribution Mechanism. Economic Inquiry 26, 585-608.

Kay, A. C., Wheeler, C. S., Bargh, J. A., \& Rossa, L., 2004. Material priming: The influence of mundane physical objects on situational construal and competitive behavioural choice, Organizational Behaviour and Human Decision Processes 95, 83-96.

Kirchsteiger, G., Rigotti, L., and Rustichini, A., 2006, Your morals might be your goods, Journal of Economic Behavior and Organization 59, 155-172.

Ledyard, J. O., 1995, Public goods: A survey of experimental research. In The Handbook of Experimental Economics (ed. A. E. Roth \& J. H. Kagel), Princeton: Princeton University Press.

Levati, M. V., Sutter, M., van der Heijden, E., 2007. Leading by example in a public goods experiment with heterogeneity and incomplete information. Journal of Conflict Resolution 51, 793-818.

Luchan, W. J., Kocher, M. G., and Sutter, M. in press. Group Polarization in the Team Dictator Game Reconsidered. Experimental Economics.

Mozley, L.H., Gur, R.C., Mozley, P.D. and Gur, R.E., 2001. Striatal Dopamine Transporters and Cognitive Functioning in Healthy Men and Women. American Journal of Psychiatry, 158, 1492-1499

Nowell, Clifford and Sarah Tinkler. 1994. "The Influence of Gender on the Provision of a Public Good," Journal of Economic Behavior and Organization 25, pp. 25-36.

Oswald A.J., Proto, E., and Sgroi, D. 2009. Happiness and Productivity. IZA Discussion Paper No. 4645. 
Sefton, M., Shupp, R., and Walker, J. M., 2007, The effects of rewards and sanctions in provision of public goods, Economic Inquiry 45, 679-690.

Smeesters, D., Warlop, L., van Avermaet, E., Corneille, O., \& Yzerbyt, V., 2003. Do not prime hawks with doves: The interplay of construct activation and consistency of social value orientation on cooperative behaviour. Journal of Personality and Social psychology 84, 972-987.

Sutter, M., Haigner, S., and Kocher, M.G. forthcoming. Choosing the Carrot or the Stick? - Endogenous Institutional Choice in Social Dilemma Situations. Review of Economic Studies.

Utz, S. 2004. Self-activation is a two-edged sword: The effects of I primes on cooperation. Journal of Experimental Social Psychology, 40: 769-776.

van Winden, F., Krawczyk, M., and Hopfensitz, A., 2008. Investment, Resolution of Risk, and the Role of Affect. Working Paper.

Vlaev, I. and Dolan, P. 2009. From changing cognitions to changing the context: A dual-route model of behaviour change. Imperial College Business School Discussion Paper no. 09-04.

Vohs, K. D., Mead, N. L., Goode, M. R., 2006, The Psychological Consequences of Money. Science 314, 1154-1156.

Williams, L. E., \& Bargh, J.A. 2008. Experiencing physical warmth promotes interpersonal warmth. Science, 322, 606-607. 
Appendix A - List of primes

\begin{tabular}{ll|ll|ll}
\hline \hline Assist & 5.679 & Smart & 3.321 & Participation & 5.75 \\
\hline Obligate & 3.25 & Unkind & 1.679 & Responsibility & 5.643 \\
\hline Generous & 3.714 & Sociable & 4.321 & Harmony & 5.5 \\
\hline Society & 4.964 & Loving & 3.786 & Mutual & 5.643 \\
\hline Community & 5.286 & Family & 4.571 & Kind hearted & 3.857 \\
\hline Helpless & 2.357 & Collective & 5.214 & Public & 4.179 \\
\hline Trust & 5.25 & United & 5.679 & Stingy & 2.143 \\
\hline Friendship & 4.786 & Cheerful & 3.321 & Equality & 4.643 \\
\hline Closeness & 4.107 & Liberal & 3.429 & Risk & 3.25 \\
\hline Moral & 3.786 & Reciprocal & 4.857 & Aid & 4.679 \\
\hline Tight & 3.179 & Unfair & 1.929 & & \\
\hline Support & 5.5 & Honest & 4.786 & & \\
\hline Sharing & 5.679 & Kindness & 4.321 & & \\
\hline Selfless & 4.071 & Malicious & 1.786 & & \\
\hline Skilful & 3.464 & Considerate & 4.714 & & \\
\hline Collaborate & 6.143 & Goodness & 4.357 & & \\
\hline Altruistic & 4.286 & Contribution & 5.571 & & \\
\hline Careless & 2 & Donation & 3.75 & & \\
\hline Charity & 3.857 & Teamwork & 6.5 & & \\
\hline Giving & 4.429 & Noble & 3.429 & & \\
\hline \hline
\end{tabular}




\section{Appendix B - Experimental instructions}

[Note: The instructions used in this experiment are presented below. The instructions in the NP-treatment differ from those in the P-treatment only with regards to the first experiment, in which subjects need to solve a word search puzzle. The instructions for the second experiment are identical between treatments.]

\section{GENERAL INFORMATION}

Welcome to this session, and thank you for participating. From now onwards please do not talk to any other participants until the session is finished.

During this session, you will take part in two experiments. You will now undertake the first experiment. You will learn about the second experiment at the beginning of that experiment, where you will receive new instructions.

\section{FIRST EXPERIMENT}

For the first experiment, you need to find the words embedded in the letter matrix according to the list presented below. The letter matrix is attached in the next page. Words can appear with letters in a straight line either from left to right or from right to left reading down or reading up, and diagonally reading either down or up. The words you need to identify are as follows:

BUTTERFLY

SALAD

WINDOW

GASOLINE

MOUNTAIN
TURTLE

CORKSCREW

HAT

PLANT

CABBAGE
UMBRELLA

LAMP

CARPET

RIVER

STAPLER
SHAMPOO

ILLUSTRATE

BUILDING

RANCH

PEACH

You will have ten minutes to solve this word-search puzzle. Your performance in this experiment will not affect at all your payment at the end of the session. At the end of this experiment you will receive a matrix indicating the answers for the word-search puzzle. 


\section{GENERAL INFORMATION}

Welcome to this session, and thank you for participating. From now onwards please do not talk to any other participants until the session is finished.

During this session, you will take part in two experiments. You will now undertake the first experiment. You will learn about the second experiment at the beginning of that experiment, where you will receive new instructions.

\section{FIRST EXPERIMENT}

For the first experiment, you need to find the words embedded in the letter matrix according to the list presented below. The letter matrix is attached in the next page. Words can appear with letters in a straight line either from left to right or from right to left reading down or reading up, and diagonally reading either down or up. The words you need to identify are as follows:

$\begin{array}{llll}\text { TEAMWORK } & \text { ASSIST } & \text { RESPONSIBILITY } & \text { SHAMPOO } \\ \text { PARTICIPATE } & \text { COMMUNITY } & \text { LAMP } & \text { COLLABORATE } \\ \text { WINDOW } & \text { MUTUAL } & \text { CARPET } & \text { UNITED } \\ \text { SHARE } & \text { PLANT } & \text { COLLECTIVE } & \text { SOCIETY } \\ \text { TRUST } & \text { HARMONY } & \text { CONTRIBUTE } & \text { SUPPORT }\end{array}$

You will have ten minutes to solve this word-search puzzle. Your performance in this experiment will not affect at all your payment at the end of the session. At the end of this experiment you will receive a matrix indicating the answers for the word-search puzzle. 


\section{SECOND EXPERIMENT}

You will now undertake the second experiment. If you read the following instructions carefully, you can, depending on the decisions that you and other participants make, earn a considerable amount of money. It is therefore very important that you read these instructions with care.

These instructions are solely for your private use. If you have any questions, please ask us.

During this experiment we will not speak in terms of Pounds, but in Guilders. During this experiment your entire earnings will be calculated in Guilders. At the end of the experiment the total amount of Guilders you have earned will be converted to Pounds at the following rate:

$$
1 \text { Guilder }=0.40 \text { Pounds }
$$

At the end of the experiment your entire earnings from the experiment will be paid to you in cash.

At the beginning of this experiment, all participants will be randomly divided into groups of three. Apart from you, there will be two more members in your group. You will not learn who the other people in your group are at any point.

In the following pages we describe the experiment in detail. At the end of this introductory information we ask you to do several control exercises which are designed to check that you have understood the decision situation.

\section{Detailed information on the experiment}

Each participant receives an endowment of 20 tokens. You have to decide how many of these 20 tokens you contribute to a group project and how many you keep for yourself. The two other members of your group have to make the same decision. They can also either contribute tokens to the project or keep tokens for themselves. You and the other members of the group can each choose any amount between 0 and 20 tokens to contribute.

Every token that you do not contribute to the project automatically belongs to you and earns you one Guilder. For the tokens contributed to the project the following happens: the project's value will be multiplied by 1.5 and this amount will be divided equally among all three members of the group. For example, if 1 token is contributed to the project, the project's value increases to 1.5 Guilders. This amount is divided equally among all three members of the group. Thus every group member receives 0.5 Guilders.

Your income from the project rises by 0.5 Guilders if you contribute one token more to the project. At the same time, the income of the other two members of the group also rises by 0.5 tokens, because they receive the same income from the project as you do. Therefore, if you contribute one token more to the project, the income from the project received by the whole group together increases by 1.5 Guilders. It is also true 
that your income rises by 0.5 Guilders if another group member contributes one token more to the project. After all three members of the group have made their decisions about the amounts of tokens they contribute to the project the total income achieved by each participant is determined.

\section{How is your income calculated from your decision?}

The income of every member of the group is calculated in the same way. As you can see, your income consists of two parts:

(1) The tokens which you have kept for yourself ('income from tokens kept') whereby 1 token $=1$ Guilder.

(2) The 'income from the project' calculated as follows: Your income from the project $=0.5$ times sum of all tokens contributed to the project by members of your group.

\section{Your total income in Guilders at the experiment is therefore:}

$(20$ - tokens contributed to the project by you $)+0.5 *($ sum of all tokens contributed to the project by members of your group)

If you do not contribute anything to the project the income from tokens kept is 20 . If you contribute for instance 7 tokens to the project your income from tokens kept is 13. At the same time, the total sum of tokens contributed to the project increases and so does your 'income from the project'.

\section{In order to explain the income calculation we give some examples. Please read them carefully:}

\section{Example 1:}

If each of the three members of the group contributes 0 tokens to the project, all three will receive an 'income from tokens kept' of 20 . Nobody receives anything from the project, because no one contributed anything. Therefore the total income of every member of the group is 20 tokens.

Calculation of the total income of every participant: $(20-0)+0.5 *(0)=20$

\section{Example 2:}

If each of the three members of the group contributes 20 tokens, there will be a total of 60 tokens contributed to the project. The 'income from tokens kept' is 0 for everyone, but each member receives an income from the project of $0.5 * 60=30$ tokens.

Calculation of the total income of every participant: $(20-20)+0.5 *(60)=30$

\section{Example 3:}

If you contribute 20 tokens, the second member 10 tokens and the third 0 tokens, the following incomes are calculated.

- Because you and the second member of the group have together contributed 30 tokens, everyone will receive $0.5 * 30=15$ Guilders from the project.

- You contributed all your 20 tokens to the project. You will therefore receive 15 Guilders in total at the end of the experiment. 
- The second member of the group also receives 15 Guilders from the project. In addition, he receives 10 Guilders as the 'income from tokens kept', because he contributed 10 tokens to the project. Thus, he receives $15+10=25$ Guilders altogether.

- The third member of the group, who did not contribute anything, also receives the 15 Guilders from the project and additionally the 20 Guilders from the 'income from tokens kept', which means $20+15=35$.

Calculation of your total income: $(20-20)+0.5 *(30)=15$

Calculation of the total income of the $2^{\text {nd }}$ group member: $(20-10)+0.5 *(30)=25$

Calculation of the total income of the $3^{\text {rd }}$ group member: $(20-0)+0.5 *(30)=35$

\section{Example 4:}

The two other members of your group contribute 20 tokens each to the project. You do not contribute anything. In this case the income will be calculated as follows:

Calculation of your total income: $(20-0)+0.5 *(40)=40$

Calculation of the total income of the $2^{\text {nd }}$ group member: $(20-20)+0.5 *(40)=20$

Calculation of the total income of the $3^{\text {rd }}$ group member: $(20-20)+0.5 *(40)=20$

When making your decision, the following input-screen will appear:

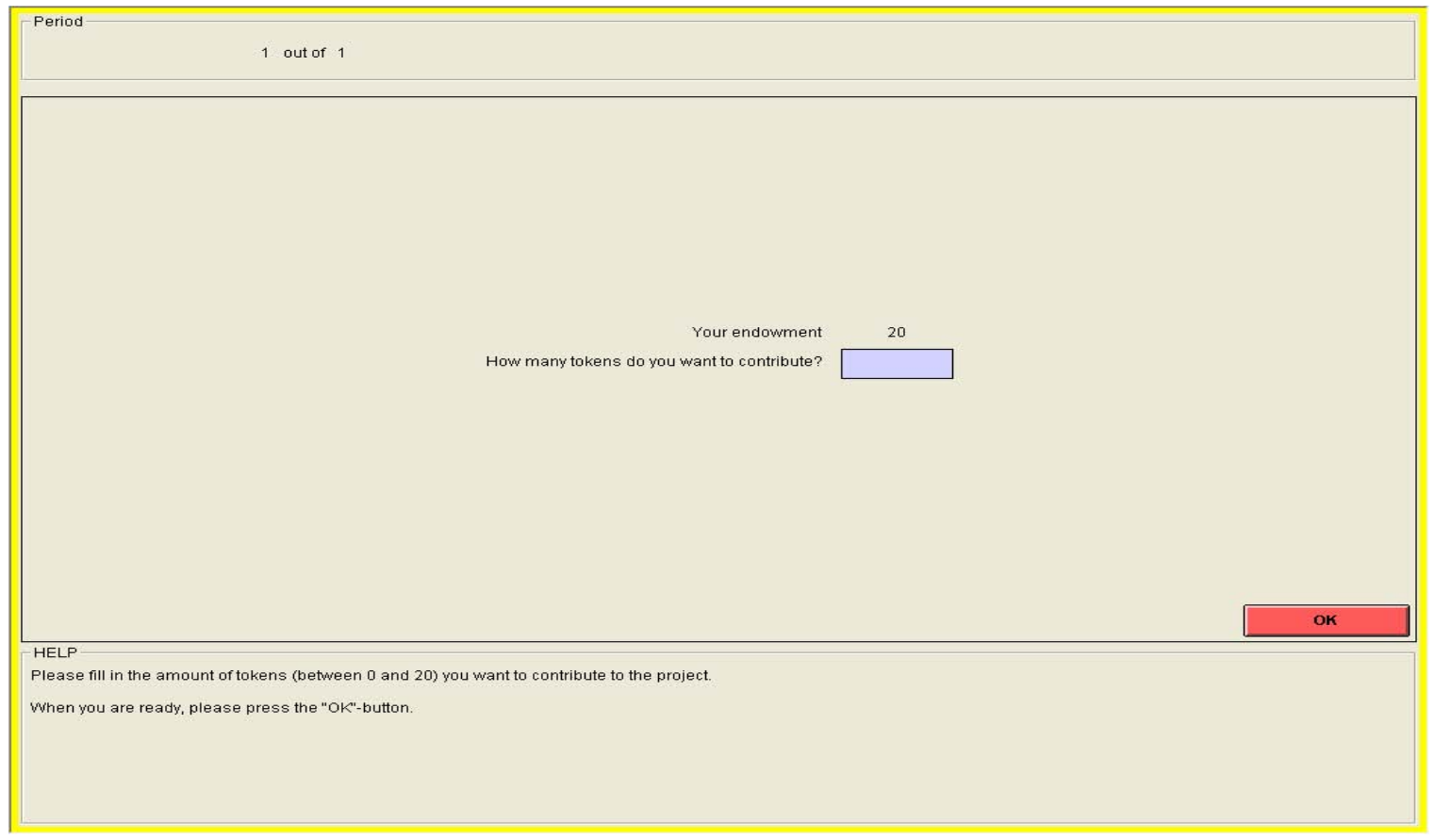

As mentioned above, your endowment in this experiment is 20 tokens. You have to decide how many tokens you contribute to the project by typing a number between 0 and 20 in the input field. This field can be reached by clicking it with the mouse. By deciding how many tokens to contribute to the project, you automatically decide how many tokens you keep for yourself. After entering the amount of tokens you contribute you must press the O.K. button using the mouse. Once you have done this, your decision can no longer be revised.

After all participants have made their decisions, your total income will be displayed on the following screen: 


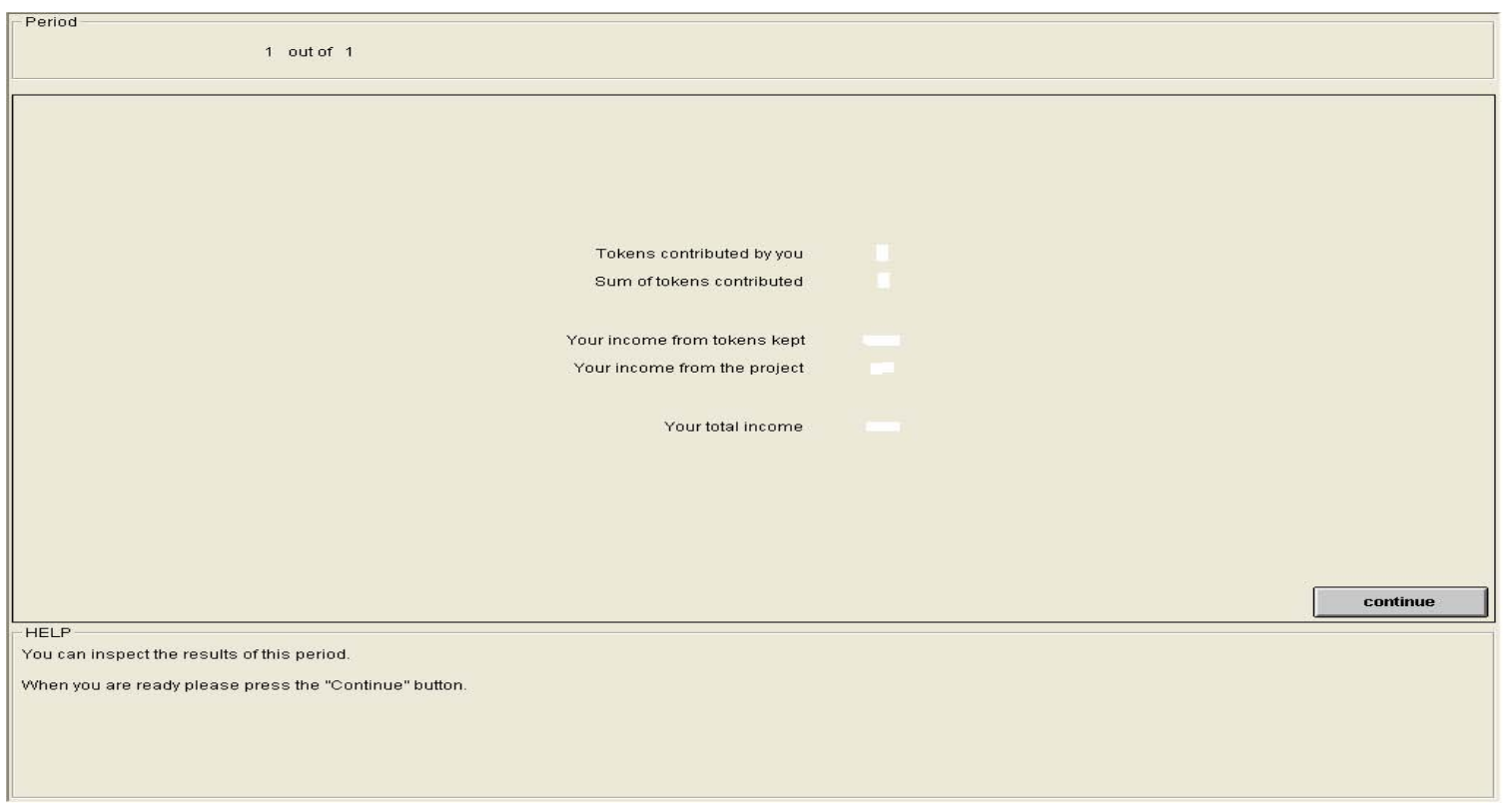

Do you have any questions?

\section{Control Questionnaire}

1. Each group member has an endowment of 20 tokens. Suppose that nobody (including yourself) contributes any token to the project.

What is your income?

What is the income of the other group members?

2. Each group member has an endowment of 20 tokens. Suppose that you contribute 20 tokens to the project. All other group members each contribute 20 tokens to the project.

What is your income?

What is the income of the other group members?

3. Each group member has an endowment of 20 tokens. Suppose that the other two group members contribute together a total of 30 tokens to the project.

What is your income if you contribute 0 tokens to the project?....

What is your income if you contribute 4 tokens to the project?.

4. Each group member has an endowment of 20 tokens. Suppose that you contribute 8 tokens to the project.

What is your income if the other group members together contribute a total of 14 tokens to the project?.

What is your income if the other group members together contribute a total of 22 tokens to the project? 


\section{Appendix C - Screenshot for eliciting emotions}

[Note: The screenshot for eliciting self-reports on emotions is presented below. The order of emotions was the same in both treatments.]

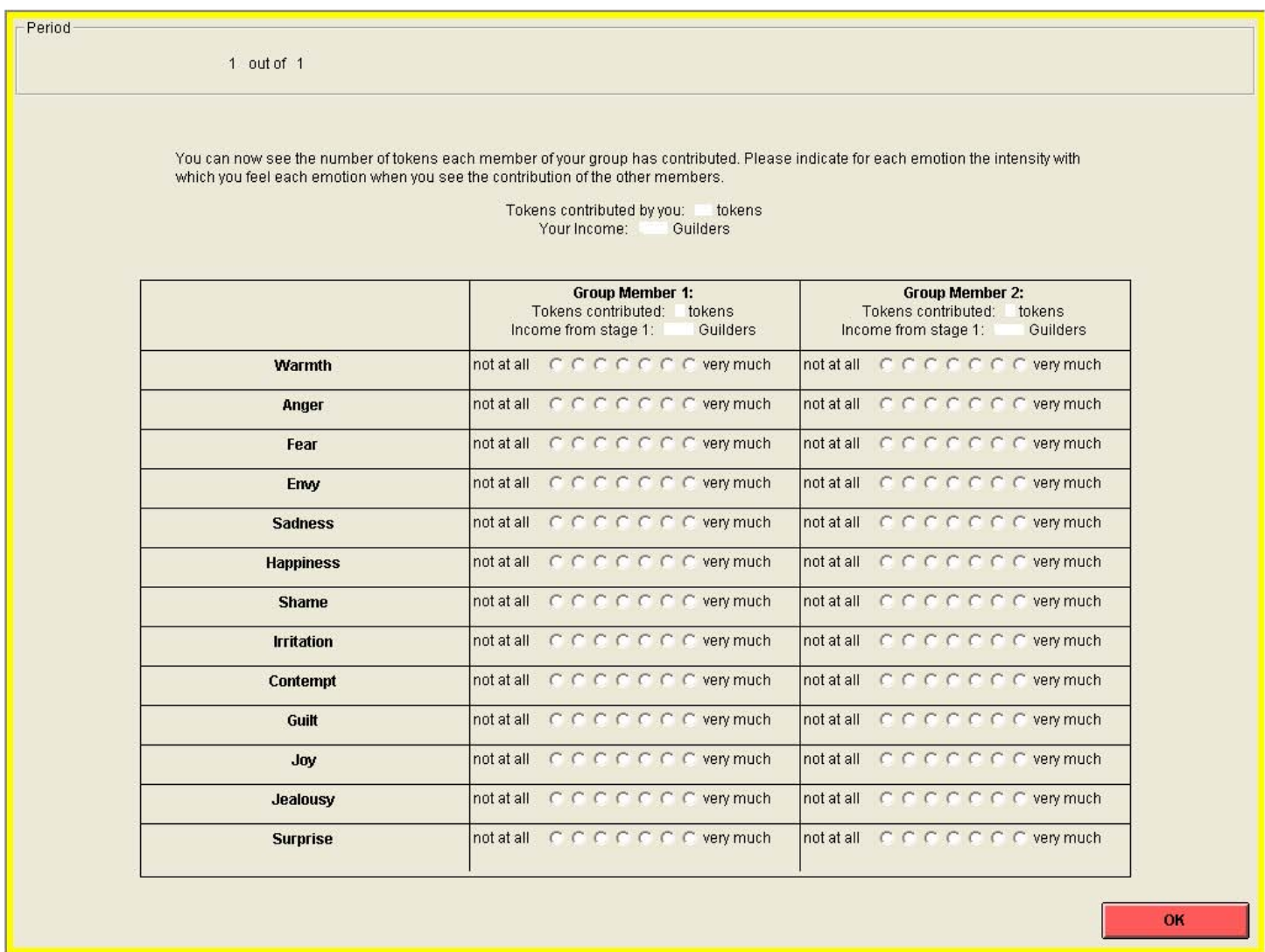

